ORIGINAL ARTICLE

\title{
Prevalence of Gastroesophageal Reflux Disease in Asthma and Chronic Obstructive Pulmonary Disease
}

\author{
MUAZZAM FUAAD ${ }^{1}$, WAHEED IQBAL ${ }^{2}$, MUHAMMAD OMAR KHAN ${ }^{3}$, AMJAD ALI $^{4}$, MUHAMMAD IMRAN $^{5}$, MUHAMMAD $^{2}$ \\ SHAHBAZ ASHRAF 6 \\ ${ }^{1}$ Assistant Professor Medicine, Medical department Rai Medical College, Sargodha \\ ${ }^{2}$ Associate Professor Medicine, department of Medicine Divisional Headquarters Teaching Hospital/ Mohtarma Benazir Bhutto Shaheed \\ Medical College, Mirpur AJK \\ ${ }^{3}$ Assistant Professor Gastroenterology KMU IMS, Kohat \\ ${ }^{4}$ Professor of Medicine BKMC/MMC, Mardan \\ ${ }^{5}$ Assistant Professor General Medicine, Mohiuddin Teaching Hospital, Mirpur AJK \\ ${ }^{6}$ Consultant Physician, THQ Hospital, Lalian, Chiniot \\ Corresponding Author: Dr Muazzam Fuaad, Assistant Professor Medicine, Medical department Rai Medical College Sargodha, Email: \\ muazzam.fuaad@gmail.com, Contact:+923009603959
}

\begin{abstract}
Background: The esophagus exposure to stomach reflexes contents (or gastric content) causes an inflammatory sensation, bitter fluid movement from the abdomen to mouth and other troublesome symptoms are generally referred to as Gastro esophageal reflux disease (GERD).

Aims: The present study aimed to evaluate the prevalence of gestroesophageal reflux disease in asthma and chronic obstructive pulmonary disease.

Materials and Methods: This multi-center cross-sectional study was carried out on 150 chronic obstructive pulmonary disease patients admitted at Medicine ward and OPD at Divisional Headquarters Teaching hospital Mirpur and KMU IMS, Kohat for six months duration from October 2020 to March 2021. All the patients of either gender having an age range between 16-70 years and met the inclusive criteria were enrolled. The demographic details such as age, gender, duration, and severity of chronic obstructive pulmonary disease, and Gastroesophageal reflux disease prevalence were recorded in proforma after obtaining informed consent in written form. Patients with a ratio of forced expiratory volume to forced vital capacity $(<70 \%)$ in one second and had no forced expiratory volume improvement after nebulization. SPSS version 20 was used for data analysis.

Results: Of the total 150 chronic obstructive pulmonary disease patients, $93(62 \%)$ were male while females were $57(38 \%)$. The overall mean age \pm SD was $54.37 \pm 16.06$ years. Chronic obstructive pulmonary disease mean duration was $8.93 \pm 5.3$ years. Out of 150 COPD patients, about $74(49.3 \%)$ had Gastroesophageal reflux disease while $76(51.7 \%)$ had no Gastroesophageal reflux disease. The GERD overall prevalence in COPD was $49.3 \%$. Based on Gastroesophageal reflux disease symptoms, very severe, severe, moderate, and mild were $26(17.6 \%)$, $23(15.4 \%), 14(9 \%)$, and $11(7.3 \%)$ respectively. As per COPD severity, the prevalence of GERD was statistically insignificant ( $\mathrm{p}-0.532)$.

Conclusion: The present study concluded a significant association between chronic obstructive pulmonary diseases with gastro esophageal reflux disease. The prevalence of gastro esophageal reflux disease was reported at $49.3 \%$ among chronic obstructive pulmonary diseases patients.

Keywords: Gastroesophageal reflux, chronic obstructive pulmonary disease, Asthma
\end{abstract}

\section{INTRODUCTION}

Gastroesophageal reflux is a common disease of the gastrointestinal system causing troublesome symptoms by stomach reflux contents [1]. It is the most ignored chronic disease until complications appear [2]. The Gastroesophageal reflux-sensitive symptoms are heartburn and regurgitation. The symptom's sensitivity and specificity of Gastroesophageal reflux is about $92 \%$ and $19 \%$ respectively compared to endoscopic monitoring (24 hours $\mathrm{pH})$. Acquiring the history of the patient could be the easiest and fastest diagnostic technique for Gastroesophageal reflux disease. Gestro-oesophageal severity and therapy response can be evaluated by frequency scale symptoms (FSSG) [3]. The asthmatic and pulmonary symptoms caused by Gastro-oesophageal reflux could be resolved with aggressive anti-reflux therapy. Gestro-oesophageal reflux intensified the pulmonary disorders (COPD). The upper respiratory symptoms higher prevalence is due to GERD [4,5]. COPD is caused by GERD besides bronchogenic carcinoma, pulmonary embolism, pneumonia, and sleep dysfunction [6]. Exacerbation marks the COPD's natural history, which speeds up the worsening of lung function leading to reduced exercise (physical activities) capacity and increases the risk of mortality [7].

The prevalence of Gastroesophageal reflux is higher in chronic obstructive pulmonary disorder compared to nonCOPD patients. Most common reason of chronic cough is Gastroesophageal reflux [8]. Gastasophagealrefflux disease (GERD) can be diagnosed with gold standard esophageal monitoring $(\mathrm{pH})$ of 24 hours and Esophagogastroduodenoscopy which visualized the esophageal muscles split [9]. GERD also affects the seriousness of the pulmonary disease. Additionally, exacerbation of acute COPD can be significantly predicted by GERD [10]. Therefore, COPD patient's early detection and treatment are critical. In COPD patients, GERD prevalence was reported between $17 \%-78 \%$ based on diagnosis and clinical approach [11]. Another study found about $62 \%$ prevalence of GERD among COPD patients 
[12]. Regardless of the COPD stage, about $26.7 \%$ prevalence of GERD was reported among COPD patients [13]. The prevalence of GERD varies based on population differences. Very few studies were conducted on GERD prevalence among COPD patients in Pakistan. The current study was carried out with the aim to evaluate the prevalence of GRED among COPD patients.

\section{METHODS}

This single-center cross-sectional study was carried out on 150 chronic obstructive pulmonary disease patients admitted at Medicine ward and OPD at Divisional Headquarters Teaching hospital, Mirpur and KMU IMS, Kohat for six months duration from October 2020 to March 2021. All the patients of either gender having an age range between 16-70 years and met the inclusive criteria were enrolled. The demographic details such as age, gender, duration, and severity of chronic obstructive pulmonary disease, and Gastroesophageal reflux disease prevalence were recorded in proforma after obtaining informed consent written form. Patients with a ratio of forced expiratory volume to forced vital capacity $(<70 \%)$ in one second and had no forced expiratory volume improvement after nebulizer. All the individual refused to consent form were excluded. The COPD stages were defined as very severe, severe, moderate, and mild with their respective limits $\geq$ $80 \%, 50-80 \%, 30-50 \%$, and $\leq 30 \%$. Ethical approval was taken from the institution's ethical board. A specially designed proforma was used for GERD prevalence data collection. The enrolled patients underwent upper gastrointestinal endoscopy with an empty stomach. Certain substances such as coffee and chocolate were prohibited for the patients on the procedure day before spirometry. Bronchoconstriction is caused by exercise and smoking hence avoided before the procedure. SPSS version 20 was used for data analysis. Tabulation form was followed for frequency and percentage calculation. GERD and COPD severity association was examined with chi-square test. P-value $<0.05$ was considered statistically significant.

\section{RESULTS}

Of the total 150 chronic obstructive pulmonary disease patients, $93(62 \%)$ were male while females were 57 (38\%). The overall mean age \pm SD was $54.37 \pm 16.06$ years. Chronic obstructive pulmonary disease mean duration was $8.93 \pm 5.3$ years. Out of 150 COPD patients, about 74 $(49.3 \%)$ had Gastroesophageal reflux disease while 76 (51.7\%) had no Gastroesophageal reflux disease as shown in Figure 1.

The GERD overall prevalence in COPD was $49.3 \%$. Based on Gastroesophageal reflux disease symptoms, very severe, severe, moderate, and mild were 26 (17.6\%), $23(15.4 \%), 14(9 \%)$, and $11(7.3 \%)$ respectively. As per COPD severity, the prevalence of GERD was statistically insignificant $(p-0.532)$. Figure 2 demonstrate the prevalence of male and females among total 150 patients. The prevalence of very severe, severe, moderate and mild COPD severity symptoms are shown in Table 1/Figure-3.

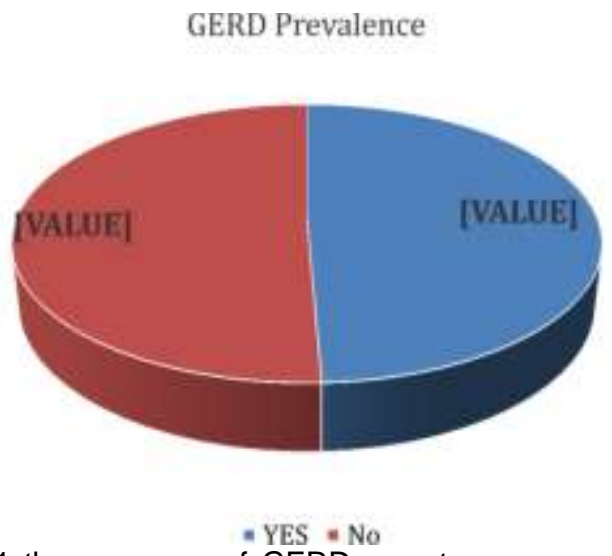

Figure-1 the presence of GERD symptoms among COPD patients $(n=150)$

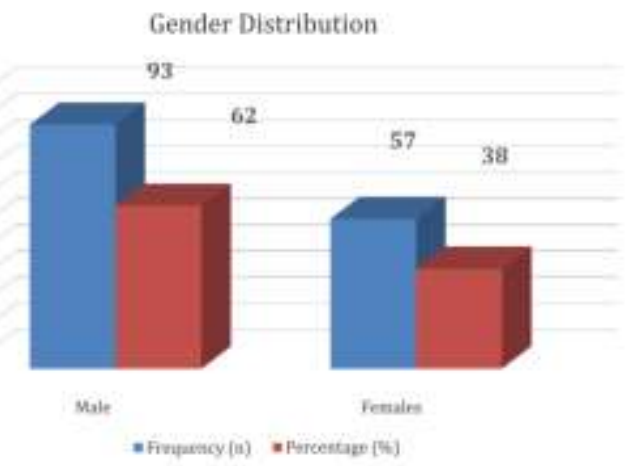

Figure-2. Gender distribution

Table-1 the COPD severity patients

\begin{tabular}{|l|l|l|}
\hline GERD Symptoms & Frequency (n) & Percentage (\%) \\
\hline Mild & 11 & 7.3 \\
\hline Moderate & 14 & 9 \\
\hline Severe & 23 & 15.4 \\
\hline Very Severe & 26 & 17.6 \\
\hline Total & 74 & 49.3 \\
\hline
\end{tabular}

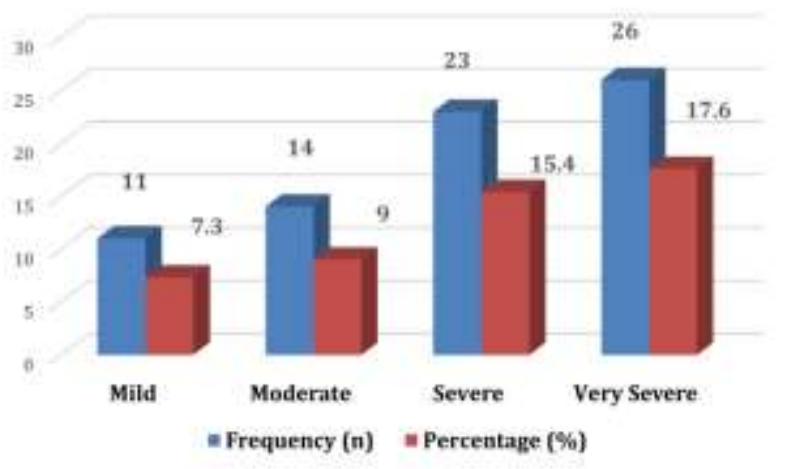

Figure-3 the COPD severity patients $(n=150)$

\section{DISCUSSION}

Gastroesophageal reflux disorder is a COPD comorbidity and prevalent gastrointestinal disorder. The present study reported an overall prevalence of $49.3 \%$ among COPD patients. Another study reported about 53.3\% [14] while 
others found $33 \%$ and between $19 \%-78 \%$ among COPD patients $[15,16]$. Compared to our study population and GERD prevalence (49.3\%). An author reported a higher prevalence of $53.6 \%$ among COPD patients [17]. However, the sample size differences were due to population variation, sample size, and age range. In our findings, the very severe, severe, moderate, and mild GERD symptoms were $17.6 \%, 15.4 \%, 9 \%$, and $7.3 \%$ respectively. Similarly, another study's findings matched our results [17]. They reported mild COPD, moderate COPD, severe COPD, and very severe COPD was $16(7.4 \%), 98(45.2 \%), 90(41.5 \%)$ and $13(6.0 \%)$ respectively. Reflux frequency and duration affects the GERD severity besides the gastro esophageal refluxate location. Smoking has been a GERD risk factor as reported while it also contributes to COPD as a major factor which indicates the GERD among COPD patients caused by nicotine and smoking [18].

Another study found that mild, Moderate, severe, and very severe GERD were $3 \%, 7 \%, 11 \%$, and $12 \%$ respectively, while asymptomatic GERD was about $67 \%$. In the current study, the frequency and percentage of very severe COPD cases were high $26(17.6 \%)$ compared to the mild COPD $11(7.3 \%)$. In our study, the prevalence of male was $93(62 \%)$ compared to the females 57 (38\%) COPD patients with overall mean age was $54.37 \pm 16.06$ years. Another study reported patient's mean age 49.34+34.12 years with male prevalence $82.2 \%$ [19]. Similarly. The average age in another study was $68.0 \pm 8.4$ years which studied older age patients compared to our research [20]. On other hand, COPD patients' mean age was $48.54 \pm 16.34$ years reported in their study [21]. The GERD developed due to COPD along with hernia and esophageal motility alteration in elderly age. Upper intestinal endoscopy was utilized for analysis of the hernia patients in their old age [22].

It is reported that pulmonary function affected by gastric contents (acid) through micro aspiration and vagal stimulation caused by bronchospasm were considered as GERD. Previous studies associated the etiology of pulmonary fibrosis, asthma, pneumonia and chronic bronchitis with GERD while a common pulmonary condition known as COPD exacts the economic cost, morbidity and mortality as a tremendous toll [22]. The current study reported GERD among COPD patients and their effects on asthma, COPD exacerbation and pulmonary function. Another study reported that esophageal acid reflux and proximal airway aspiration caused the asthma symptoms. Number of studies proved the increased airway resistance demonstrated in acidified trachea supported by another researcher's hypothesis which stated that respiratory symptoms and GOR in some patients are due to the aspiration scintigraphic demonstration of airway radiolabeled isotopes. Others showed esophageal reflux causing tracheal acidification [23].

\section{CONCLUSION}

The present study concluded a significant association between chronic obstructive pulmonary diseases with gastro esophageal reflux disease. The prevalence of gastro esophageal reflux disease was reported at $49.3 \%$ among chronic obstructive pulmonary diseases patients.

\section{REFERENCES}

1. PRASAD B. Chronic Obstructive Pulmonary Disease (COPD). International Journal of Pharmacy Research \& Technology. 2020;10(1):67-71.

2. Duangrithi D, Saiprom K, SaeTew J, Sa-u Y. Impact of exacerbation on the errors of inhaler techniques in COPD patients. J. Appl. Pharm. Sci. 2017;7:84-9.

3. Subramanian CR, Triadafilopoulos G. Refractory gastroesophageal reflux disease. Gastroenterology Report. 2015;3:41-53.

4. Kim J, Lee JH, Kim Y, Kim K, Oh YM, Yoo KH, Rhee CK, Yoon HK, Kim YS, Park YB, Lee SW. Association between chronic obstructive pulmonary disease and gastroesophageal reflux disease: a national cross-sectional cohort study. BMC pulmonary medicine. 2013 Dec;13(1):1-0.

5. Nafees AA, Fatmi Z, Kadir MM, Sathiakumar N. Chronic bronchitis and chronic obstructive pulmonary disease (COPD) among Textile workers in Karachi, Pakistan. Journal of the College of Physicians and Surgeons Pakistan. 2016;26(5):384.

6. Masjedi M, Ainy E, Zayeri F, Paydar R. Assessing the prevalence and incidence of asthma and chronic obstructive pulmonary disease in the Eastern Mediterranean region. Turkish thoracic journal. 2018 Apr;19(2):56

7. Khan GM, Zuberi FF, uz Zahra SB, Ghafoor L. Frequency of Blood Eosinophilia in newly diagnosed Chronic Obstructive Pulmonary Disease patients. Pakistan Journal of Medical Sciences. 2020 May;36(4):750.

8. Hafeez S, Butt A, Hussain A, Hashim MA, Ahmad S, Ahmad A. Gastroesophageal Reflux Disease In Patients With Chronic Obstructive Pulmonary Disease. Ann Pak Inst Med Sci.2020;17(1):71-4.

9. Broers C, Tack J, Pauwels A. gastro-oesophageal reflux disease in asthma and chronic obstructive pulmonary disease. Alimentary pharmacology \& therapeutics. 2018 Jan;47(2):176-91.

10. Iliaz S, lliaz R, Onur ST, Arici S, Akyuz U, Karaca C, Demir K, Besisik F, Kaymakoglu S, Akyuz F. Does gastroesophageal reflux increase chronic obstructive pulmonary disease exacerbations?. Respiratory medicine. 2016 Jun 1;115:20-5.

11. Wahab A, Haq ZU, Waqas A, Ashraf S, Farooqi R, Ullah R. Frequency of Gastroesophageal reflux disease in patients with Chronic Obstructive Pulmonary disease admitted to Pulmonology Ward Khyber Teaching Hospital . Pak J Chest Med 2019; 25 (1):27-31.

12. Lee AL, Goldstein RS. Gastroesophageal reflux disease in COPD: links and risks. International journal of chronic obstructive pulmonary disease. 2015;10:1935.

13. Clarrett DM, Hachem C. Gastroesophageal Reflux Disease (GERD). Missouri medicine. 2018;115(3):214.

14. Yamasaki T, Hemond C, Eisa M, Ganocy S, Fass R. The changing epidemiology of gastroesophageal reflux disease: are patients getting younger? Journal of neurogastroenterology and motility. $2018 ; 24(4): 559$.

15. Hsu CK, Lai CC, Wang K, Chen L. Risk of lung cancer in patients with gastro-esophageal reflux disease: a populationbased cohort study. PeerJ. 2016 Dec 20;4:e2753.

16. Ghebre YT, Raghu G. Idiopathic pulmonary fibrosis: novel concepts of proton pump inhibitors as antifibrotic drugs. American journal of respiratory and critical care medicine. 2016 Jun 15;193(12):1345-52.

17. Lin HC, Xirasagar S, Chung SD, Huang CC, Tsai MC, Chen $\mathrm{CH}$. Fewer acute respiratory infection episodes among patients receiving treatment for gastroesophageal reflux disease. PloS one. 2017;12(2):e0172436.

18. Khan HN, Suleman A, Ullah R, Abdullah A, Naz S. Gastro oesophageal reflux diseases in chronic obstructive pulmonary disease patients. J Ayub Med Coll Abbottabad 2018;30(1):64-6. 
19. Usman U, Irfan M, Faisal M. Frequency of GERD in COPD Patients. APMC 2016;10(3):111-114.

20. Tsai C-L, Lin Y-H, Wang M-T, Chien L-N, Jeng C, Chian CF, et al. Gastro-oesophageal reflux disease increases the risk of intensive care unit admittance and mechanical ventilation use among patients with chronic obstructive pulmonary disease: a nationwide population-based cohort study. Crit Care. 2015;19:110.

21. Benson VS, Müllerová H, Vestbo J, Wedzicha JA, Patel A, Hurst JR, et al. Associations between gastro-oesophageal reflux, its management and exacerbations of chronic obstructive pulmonary disease. Respir Med. 2015;109:114754.

22. Bor S, Kitapcioglu G, Solak ZA, Ertilav M, Erdinc M.Prevalence of gastroesophageal reflux disease in patients with asthma and chronic obstructive pulmonary disease. $J$ Gastroenterol Hepatol. 2010 Feb;25(2):309-13.

23. Huang, C., Liu, Y. \& Shi, G. A systematic review with metaanalysis of gastroesophageal reflux disease and exacerbations of chronic obstructive pulmonary disease. BMC Pulm Med 20, 2 (2020). 